\title{
Utilization of Integrated Community Case Management of Childhood Illnesses at Health Posts in Southern Ethiopia
}

This article was published in the following Dove Press journal:

Pediatric Health, Medicine and Therapeutics

\author{
Asefa Berhanu' \\ Mihiretu Alemayehu (iD) ${ }^{2}$ \\ Kassa Daka ${ }^{2}$ \\ Wakgari Binu $\mathbb{D}^{2}$ \\ Mohammed Suleiman $\mathbb{D}^{3}$ \\ 'Wolaita Zone Health Department, \\ Wolaita Sodo, Ethiopia; ${ }^{2}$ Wolaita Sodo \\ University, College of Health Sciences \\ and Medicine, School of Public Health, \\ Wolaita Sodo, Ethiopia; ${ }^{3}$ Wolaita Sodo \\ University, College of Health Sciences \\ and Medicine, Department of Anesthesia, \\ Wolaita Sodo, Ethiopia
}

Purpose: Even if strategic actions were undertaken to tackle common childhood illnesses, Ethiopia still stood as one of the six countries accounting for half of the global under-five deaths. So this study aimed to assess the utilization of integrated community case management during childhood illness at health posts in the study area.

Methods: A community-based cross-sectional study was conducted using a multistage sampling technique that includes 633 sick under-five children with common childhood illnesses. The data was entered into EpiData 3.1 and exported to SPSS 20 for further analysis. Descriptive statistics, bivariate and multivariate logistic regression analyses were computed and adjusted odds ratio within $95 \%$ confidence interval was used to measure the statistical association between variables.

Results: Out of the planned 633 participant, 624 caregivers underwent all the study components making the response rate $98.6 \%$. The study indicated that only $10.6 \%$ of the sick children sought care from health posts. Income (AOR $=2.99,95 \%$ CI: $1.37-6.53$ ), previous service utilization $(\mathrm{AOR}=6.66,95 \% \mathrm{CI}$ : 1.81-24.04), awareness of service availability $(\mathrm{AOR}=4.74,95 \% \mathrm{CI}: 1.39-12.10)$, ownership of health insurance (AOR = 2.63, 95\% CI: 1.45-4.76), distance $(\mathrm{AOR}=5.23,95 \% \mathrm{CI}: 1.69-10.19)$ and type of illness $(\mathrm{AOR}=2.97,95 \% \mathrm{CI}: 1.41-6.25)$ were the associated factors.

Conclusion: The low utilization of integrated community case management insights to focus on availing additional well-equipped health posts, creating community awareness on services at health posts and at what time the services are given to address the problem of the majority.

Keywords: ICCM, health post utilization, fever, diarrhea, cough, Kindo Didaye

\section{Plain Language Summary}

Evidence showed that Ethiopia still stood as one of the six countries accounting for half of the global under-five deaths. Even if Ethiopia had initiated the integrated community case management (ICCM) program a long time ago, there is a scarcity of data dealing with ICCM utilization. Available studies ignored remote areas at which the community is suffering from poor infrastructures due to difficult topography like our study area.

We conducted the study in one of the harsh areas in southern Ethiopia, Kindo Didaye district, which is highly mountainous and hard to reach, with poor infrastructures. We used a multistage sampling strategy to recruit the required sample size. We conducted a survey using identification panel questions in six randomly selected kebeles (the smallest administrative unit in Ethiopia) to identify households (HHs) with under-five sick children. Then we recruited proportionally allocated HHs fulfilling criteria until we obtained the sample size using random sampling technique.
Correspondence: Wakgari Binu Wolaita Sodo University, College of Health Sciences and Medicine, School of Public Health, P.o. Box: 138, Wolaita Sodo, Ethiopia

Tel +251910107704

Email nubonsa@gmail.com 
EpiData v3.1 and SPSS v20 were used for data management. Bivariate and multivariate logistic regression analysis were computed to control confounders and to identify predictors of ICCM utilization. The overall ICCM utilization at health posts (HPs) in this study was very low while childhood illness was prevalent in the area. This study identified factors influencing the service utilization among participants. The community need to be continually aware of the time when health posts are open for health services. Also providing additional equipped HPs to address the problem of the majority is the cutting issue. Even if limited number of studies reported suboptimal use of HPs for ICCM in other parts of Ethiopia, this study will provide recent evidence on the issue for health managers and stakeholders.

\section{Introduction}

Globally under-five deaths dropped to 5.3 million in 2018 from 12.6 million in 1990. Despite exhaustive progress made, Sub-Saharan Africa continues to be the region with the highest child mortality rate in the world, 78 deaths per 1000 live births mostly from preventable causes such as pneumonia, diarrhea, and malaria. ${ }^{1}$

Even though Ethiopia has significantly reduced underfive child deaths from 204 per 1000 live births in 1990 to 59 per 1000 live births in 2017, 518 children are dying every day, mostly of preventable or treatable diseases such as diarrhea, malaria, and pneumonia. Also, Ethiopia is one of the six countries (India, Nigeria, Pakistan, the Democratic Republic of the Congo, Ethiopia, and China) accounting for half of the global under-five deaths. ${ }^{1,2}$

Countries identified integrated community case management (ICCM) as an effective evidence-based strategy to increase coverage of lifesaving interventions and to reduce preventable child deaths where access to health services is limited. The aim of ICCM strategy was to improve access to treatment of diarrhea, fever and pneumonia by providing evidence-based free treatments to the largely rural population, where there is a lack of access to private clinics, public health centers, and higher-level facilities. $^{3-5}$

In response to the high child mortality, the government of Ethiopia had introduced the implementation of ICCM in 2010 after the health policy update. ${ }^{3}$ The government has been implementing ICCM strategy through the platform of the Health Extension Program (HEP). The government initiated HEP to scale up the essential health services by reaching the people at the grassroots level in particular to the underserved rural population. It was designed based on the concept and principles of comprehensive primary health care. ${ }^{4,5}$ In this program, health extension workers (HEWs) were trained to assess, classify and treat common childhood illnesses like diarrhea, malaria, pneumonia and severe acute malnutrition among under-five children. In this regard, HEWs were providing the service in rural communities at HPs since 2010 to reduce under-five mortality to 29 per 1000 live births by $2020 .^{6-8 \text {, }}$

The government of Ethiopia has also made a series of efforts like an integration of ICCM into health policy, scale-up of ICCM implementation, and removing the ICCM utilization barriers being with different local and global development partners (Non-Government Organizations) to reduce under-five mortality. Despite these efforts made, health facility-based evidence showed a low level of ICCM utilization among under-five sick children in the country. ${ }^{9-12}$

Even if the ICCM program was initiated a long time ago in the country, there is a scarcity of data in the study area that dealt with ICCM utilization. Available evidence ignored remote areas at which the community is suffering from poor infrastructures due to difficult topography like our study area. Therefore, this study has assessed the ICCM utilization and influencing factors. The findings will provide evidence-based information to regional and local health managers, and health extension workers. The findings will also provide recent evidence for concerned bodies to strengthen community-based interventions and minimize the barriers of ICCM utilization at HPs. So the utilization of the finding helps to reduce child morbidity and mortality in the community.

\section{Materials and Methods Study Setting and Design}

A community-based cross-sectional study was conducted from May 1st to 21st, 2019 in Kindo Didaye district, Wolaita zone, southern Ethiopia. The district is one of the 16 districts and 6 urban administrative towns in the Wolaita zone, located at 475 kilometers from Addis, capital of Ethiopia. The district is highly mountainous and the hardest to reach, with poor infrastructure areas in the zone. There are 22 Kebeles in the district, of which 19 are rural kebeles and 3 are semi-urban kebeles with an estimated population of 129,246 in 2017 as projected from the 2007 census. The number of under-five aged children is 20,162 accounting for $15.6 \%$ of the total population.

Regarding a health facility, there are 25 HPs each with two HEWs implementing the 17 Ethiopian health extension 
packages including ICCM and CBNC, 3 health centers, 1 primary hospital and 4 medium private clinics serving the community with a range of health services in the district (Kindo Didaye administration annual report, 2018).

\section{Population and Sampling}

We had included caregivers of children aged 0-59 months having an episode of coughing or fever or diarrhea during the two weeks preceding the survey. We had excluded under-five sick children whose caregivers were unable to hear and speak from the study.

The sample size was estimated using a single population formula based on the survey done by L10K in South Nations, Nationalities and People's Regional State of Ethiopia. We have considered diarrhea, fever and pneumonia to determine the sample size. We used the proportion of children with diarrhea-sought care from an appropriate provider (48.28\%) as it has given a maximum sample size. ${ }^{13}$ Considering 5\% marginal error at $95 \%$ confidence level, design effect of 1.5 (accounting for correlation of observations among kebeles) and $10 \%$ compensation for non-response giving 633 caregivers were planned to be interviewed.

Then a multistage sampling strategy used to recruit the representative sample of respondents. At the first stage, out of the 22 kebeles (smallest administrative unit), 6 kebeles were selected randomly. In the second stage, we conducted a survey using HH identification panel questions [Table S1] before actual data collection to identify the total number of HHs in each selected kebele. The aim of the survey was to identify total HHs with under-five sick children. We had given specific codes (i.e., 0001sc, 0002sc, etc.)(sc: specific code given to indicate under-five sick child fulfilling inclusion criteria is present in that $\mathrm{HH}$.) for $\mathrm{HHs}$ fulfilling inclusion criteria and used as a sampling frame. We allocated total sample size proportionally among the selected six kebeles. Then we recruited HHs fulfilling criteria in each kebele until we obtained the representative sample size in the respective kebele. In a case when there was more than one under-five sick children in a $\mathrm{HH}$, we selected one of the children using lottery method (Figure S1). A revisit was scheduled for those who were not at home during the first visit. Respondents were considered as non-respondent if missed after two revisits on different days.

\section{Tools and Data Collection Process}

The data was collected using structured intervieweradministered questionnaires from caregivers. The questionnaire was adapted from Andersen's Health Service
Utilization Model,,${ }^{14}$ and experts from the health extension program of the Wolaita zone were consulted. After preparing in English, it was translated to the local language (Wolaytato doona) and back-translated to English by different language experts to ensure consistency. Six diploma nurses as data collectors and two masters in public health as supervisors, with prior experience from other districts, participated in data collection. They were given two days of training on the objective of the study, the process of data collection, and how to handle data a day before the actual data collection.

\section{Key Terms and Measurement ICCM}

ICCM refers to the concurrent management of more than one common childhood illness. In this study, we focused on the common contributors of childhood illness and deaths in Ethiopia: cough, fever and diarrhea. ${ }^{15}$

\section{ICCM Utilization}

The outcome variable which was measured as a percentage of caregivers, among the study participants, visited HPs for their sick children in the last two weeks for either cough or fever or diarrhea $(n=624)$. A caregiver had utilized the ICCM if she/he reported that she/he visited HPs after recognizing one of the three childhood illnesses on her/his child otherwise they were not utilized.

\section{Data Quality Control and Data Analysis}

To ensure the quality of the data, the questionnaire was pre-tested in a neighboring district a week before the actual data collection to ensure clarity, wordings, logical sequence, skipping patterns, and modifications were done accordingly. Moreover, we made adequate follow ups throughout the data collection period. Supervisors had checked the filled questionnaires on a daily basis for completeness and necessary corrections were made in a timely fashion while the overall activities were monitored by the principal investigator.

We designed the data entry format using the statistical software EpiData 3.1 and exported to the statistical package for social science (SPSS) version 20 for further analysis. We computed a principal component analysis (PCA) to generate the wealth index of HHs. We computed descriptive summary measures to describe the sociodemographic characteristics of the study participants. We had computed bivariate and multivariable logistic regression analysis to assess the association between variables. 
The significance of the association between dependent and independent variables was declared using adjusted odds ratio along with their $95 \%$ CI. Hosmer-Lemeshow goodness-of-fit was done to test the model fitness $(P=0.57) .{ }^{16}$ Moreover, multi-collinearity among independent variables was checked using the variance inflation factor (VIF) in which all the variables in the final model were below the recommended cutoff value of $10(\mathrm{VIF}=1.86)$.

\section{Result}

\section{Socio-Economic and Demographic}

\section{Characteristics}

Out of the total, 624 caregivers of under-five sick children had participated in this study making the response rate $98.6 \%$. The mean age of respondents was 28.75 (SD = 5.4) years and $62 \%$ were greater than 30 years old. Significant proportions of caregivers, $283(45.4 \%)$ were living 1-2 hours away from the HP in their kebele. The mean age of the under-five sick children was 20.5 (SD = 4.8) months while the majority $180(29 \%)$, were in the 24-35 months age category and 225 (36\%) were sick with diarrhea (Table 1).

\section{ICCM Service Utilization and Health Care-Seeking Behaviors}

In this study, only half $312(50 \%)$ of mothers sought health care services from different sources, $66(10.6 \%)$ from HP, $78(12.5 \%)$ from the health center, 58 (9.3\%) from hospitals, 54 (8.7\%) from traditional healers, 39 (6.3\%) home treatment, and 17 (2.7\%) from private clinics. The majority of caregivers, 525 (84\%), had no awareness of ICCM availability at HP. Besides, only 174 (28\%) and 140 $(22.5 \%)$ of caregivers owned community health insurance and were knowledgeable about child danger signs, respectively ([Table 2).

The magnitude of ICCM utilization at HP among under-five sick children in the study area was found to be $66(10.6 \%)(95 \%$ CI: $8-13 \%)$, while the majority, 558 (89.4\%) were non-users of ICCM at HP ([Figure 1). Half of the participants had sought health cares from different sources while 246 (78.85\%) of them had not sought health care from HPs for different reasons. The main reported reasons not to use ICCM from HPs were uncertainty of the time when HP is open $86(35 \%$; $95 \%$ CI: 29.4-38.2), HP located too far from their home 81 (33\%; 95\% CI: 27.0-37.8), HP has no necessary
Table I Socioeconomic and Demographic Characteristics of Respondents in Kindo Didaye District, Southern Ethiopia, 2019 $(n=624)$

\begin{tabular}{|c|c|c|c|}
\hline \multicolumn{2}{|l|}{ Variable Categories } & \multirow{2}{*}{$\begin{array}{l}\text { Frequency } \\
238 \\
386\end{array}$} & \multirow{2}{*}{$\begin{array}{l}\text { Percentage } \\
38 \\
62\end{array}$} \\
\hline $\begin{array}{l}\text { Maternal age in years } \\
(S D=5.4)\end{array}$ & $\begin{array}{l}<30 \\
\geq 30\end{array}$ & & \\
\hline $\begin{array}{l}\text { Marital status of } \\
\text { a mother }\end{array}$ & $\begin{array}{l}\text { Married } \\
\text { Single } \\
\text { Others }^{\mathrm{a}}\end{array}$ & $\begin{array}{l}585 \\
23 \\
16\end{array}$ & $\begin{array}{l}93.7 \\
3.7 \\
2.6\end{array}$ \\
\hline Occupation of mother & $\begin{array}{l}\text { Employ } \\
\text { Merchant } \\
\text { Housewife } \\
\text { Daily } \\
\text { laborer }\end{array}$ & $\begin{array}{l}10 \\
102 \\
507 \\
5\end{array}$ & $\begin{array}{l}1.6 \\
16.3 \\
81.3 \\
0.8\end{array}$ \\
\hline $\begin{array}{l}\text { The educational level of } \\
\text { a mother }\end{array}$ & $\begin{array}{l}\text { Unable to } \\
\text { read and } \\
\text { write } \\
\text { Grade I-8 } \\
\text { Grade } \geq 9\end{array}$ & $\begin{array}{l}495 \\
103 \\
26\end{array}$ & $\begin{array}{l}79.3 \\
\\
16.5 \\
4.2\end{array}$ \\
\hline $\begin{array}{l}\text { Educational status of } \\
\text { the father }\end{array}$ & $\begin{array}{l}\text { Unable to } \\
\text { write and } \\
\text { read } \\
\text { Grade I-8 } \\
\text { Grade } \geq 9\end{array}$ & $\begin{array}{l}209 \\
25\end{array}$ & $\begin{array}{l}62.5 \\
33.5 \\
4\end{array}$ \\
\hline Occupation of father & $\begin{array}{l}\text { Employ } \\
\text { Merchant } \\
\text { Farmer } \\
\text { Daily } \\
\text { laborer }\end{array}$ & $\begin{array}{l}20 \\
56 \\
522 \\
26\end{array}$ & $\begin{array}{l}3.2 \\
9 \\
83.7 \\
4.1\end{array}$ \\
\hline Region & $\begin{array}{l}\text { Protestant } \\
\text { Orthodox } \\
\text { Others }\end{array}$ & $\begin{array}{l}418 \\
188 \\
18\end{array}$ & $\begin{array}{l}66.9 \\
30.1 \\
3\end{array}$ \\
\hline HHs Wealth Status & $\begin{array}{l}\text { Poor } \\
(25 \%) \\
\text { Medium } \\
(50 \%) \\
\text { Rich (25\%) }\end{array}$ & $\begin{array}{l}195 \\
238 \\
189\end{array}$ & $\begin{array}{l}31.8 \\
38 \\
30.2\end{array}$ \\
\hline Family size in $\mathrm{HH}$ & $\begin{array}{l}\leq 5 \\
\text { members } \\
>5 \\
\text { members }\end{array}$ & $\begin{array}{l}303 \\
321\end{array}$ & $\begin{array}{l}48.6 \\
51.4\end{array}$ \\
\hline $\begin{array}{l}\text { Age of child in months } \\
(\mathrm{SD} \pm 4.8)\end{array}$ & $\begin{array}{l}0-11 \\
12-23 \\
24-35 \\
36-47 \\
48-59\end{array}$ & $\begin{array}{l}57 \\
86 \\
180 \\
147 \\
154\end{array}$ & $\begin{array}{l}9 \\
14 \\
29 \\
23.5 \\
24.5\end{array}$ \\
\hline Child gender & Male & 299 & 48 \\
\hline
\end{tabular}

(Continued) 
Table I (Continued).

\begin{tabular}{|l|l|l|l|}
\hline \multicolumn{2}{|l|}{ Variable Categories } & Frequency & Percentage \\
\hline & Female & 325 & 52 \\
\hline Distance from home to & $0-30$ & 117 & 18.9 \\
HP (travel time in & $31-60$ & 167 & 27 \\
minutes) & $61-120$ & 283 & 45.4 \\
& $>120$ & 57 & 8.7 \\
\hline
\end{tabular}

Notes: a Widowed, Divorced, ${ }^{\mathrm{b}} \mathrm{Catholic}$, Adventist, Traditional.

medication $74(30 \%)$, and alternative care-seeking $5(2 \%$; 95\% CI: 1.6-3.0), [Figure 2].

\section{Factors Associated with ICCM Utilization at HP}

During multivariate logistic regression analysis, the income of the household, previous use of HP for child illness, ownership of community health insurance, awareness of ICCM availability at HP, walking distance from home to HP in their kebele and type of child illness were found to be significantly associated with ICCM utilization at HP (see Table 3).

\section{Discussion}

This study has attempted to measure the level of ICCM utilization and identified factors that are influencing ICCM utilization among caregivers with under-five sick children.

The findings of this study revealed that only $10.6 \%$ (95\% CI: $8-13 \%$ ) of under-five children sick with diarrhea, fever, and cough/pneumonia took treatment from HP. This result is in line with other studies conducted in the Oromia region of the Jimma zone (10.8\%), Hararge zone (10.8\%), and Agarfa woreda (10.5\%). ${ }^{12,17}$ However, it was lower than the result of the survey conducted by L10K in Amhara, SNNP, and Tigray regions (16.1\%). ${ }^{13}$ The possible reason for the difference might be due to socioeconomic and demographic differences. This also might result from differences in the study settings because the previous study was conducted in districts supported by the L10K project on the ICCM program.

Households in the poor wealth index category were about three times more likely to utilize ICCM at HPs for their sick children than those in the rich wealth index category. This finding is similar to other studies done in Kenya and Uganda. ${ }^{18,19}$ This might be justified as health services at HPs are free of charge while different costs are
Table 2 Health Care-Seeking Behaviors of Caregivers for UnderFive Sick Children with Common Childhood Illnesses in Kindo Didaye District, Southern Ethiopia, 2019

\begin{tabular}{|c|c|c|c|}
\hline $\begin{array}{l}\text { Sources of } \\
\text { Healthcare } \\
\text { Seeking }\end{array}$ & & Frequencies & $\begin{array}{l}\text { Percentage } \\
\text { (\%) }\end{array}$ \\
\hline $\begin{array}{l}\text { Reported type of } \\
\text { child illness }\end{array}$ & $\begin{array}{l}\text { Cough } \\
\text { Fever } \\
\text { Diarrhea }\end{array}$ & $\begin{array}{l}219 \\
180 \\
225\end{array}$ & $\begin{array}{l}35 \\
29 \\
36\end{array}$ \\
\hline $\begin{array}{l}\text { Health care services } \\
\text { sought }\end{array}$ & $\begin{array}{l}\text { Yes } \\
\text { No }\end{array}$ & $\begin{array}{l}312 \\
312\end{array}$ & $\begin{array}{l}50 \\
50\end{array}$ \\
\hline $\begin{array}{l}\text { Sources of health } \\
\text { care seeking }\end{array}$ & $\begin{array}{l}\text { Health } \\
\text { post } \\
\text { Health } \\
\text { center } \\
\text { Hospitals } \\
\text { Traditional } \\
\text { healers } \\
\text { Home } \\
\text { treatment } \\
\text { Privet } \\
\text { clinic }\end{array}$ & $\begin{array}{l}66 \\
78 \\
58 \\
54 \\
39 \\
17\end{array}$ & $\begin{array}{l}10.6 \\
12.5 \\
9.3 \\
8.7 \\
6.3 \\
2.7\end{array}$ \\
\hline $\begin{array}{l}\text { Awareness of ICCM } \\
\text { services at HP }\end{array}$ & $\begin{array}{l}\text { Yes } \\
\text { No }\end{array}$ & $\begin{array}{l}99 \\
525\end{array}$ & $\begin{array}{l}16 \\
84\end{array}$ \\
\hline $\begin{array}{l}\text { Previous use of } \\
\text { services at HP }\end{array}$ & $\begin{array}{l}\text { Yes } \\
\text { No }\end{array}$ & $\begin{array}{l}104 \\
520\end{array}$ & $\begin{array}{l}16.8 \\
83.2\end{array}$ \\
\hline $\begin{array}{l}\text { Owner of } \\
\text { community health } \\
\text { insurance }\end{array}$ & $\begin{array}{l}\text { Yes } \\
\text { No }\end{array}$ & $\begin{array}{r}174 \\
450\end{array}$ & $\begin{array}{l}28 \\
72\end{array}$ \\
\hline $\begin{array}{l}\text { Knowledge of child } \\
\text { danger signs }\end{array}$ & $\begin{array}{l}\text { Yes } \\
\text { No }\end{array}$ & $\begin{array}{l}140 \\
484\end{array}$ & $\begin{array}{l}22.5 \\
77.5\end{array}$ \\
\hline $\begin{array}{l}\text { History of index } \\
\text { child death }\end{array}$ & $\begin{array}{l}\text { Yes } \\
\text { No }\end{array}$ & $\begin{array}{l}31 \\
593\end{array}$ & $\begin{array}{l}5 \\
95\end{array}$ \\
\hline
\end{tabular}

needed to utilize health services from higher health facilities.

The current study also revealed that caregivers who had previously utilized health services at HPs for child illness were about seven times more likely to utilize ICCM at HPs for their sick children than those who never utilized HPs for child illness. This finding is supported by findings from other studies done in Ethiopia and Kenya. ${ }^{18,20}$ The 


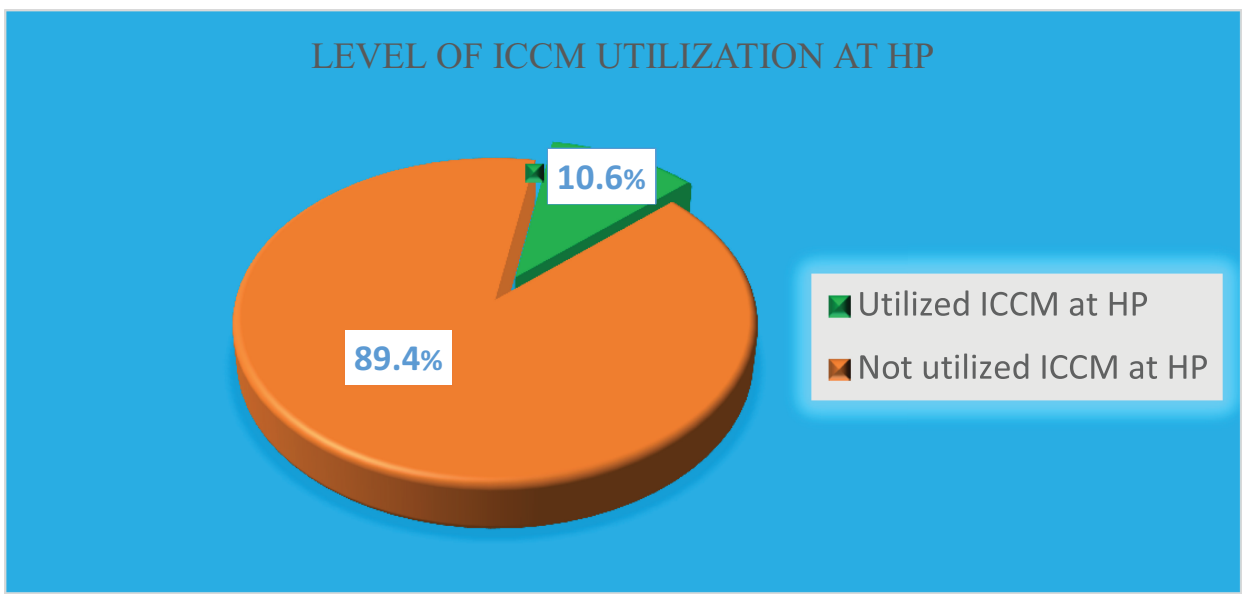

Figure I ICCM utilization at HPs in Kindo Didaye district, Ethiopia, 2019.

possible explanation for this might be exposure to HP for health services encourages caregivers to utilize ICCM.

Caregivers who were not a member of the community health insurance were about three times more likely to utilize ICCM at HP for their sick children. This is in contrast with the fact that members of the community health insurance were more likely to utilize health services than their counterparts. ${ }^{21}$ In Ethiopia, all health care services at HPs are free so that those families who cannot afford to pay for community health insurance every year might prefer to utilize ICCM at HP. This possible justification is also supported by the evidence in our finding that caregivers from poor HHs were more likely to utilize health services at HPs.

Mothers who have awareness of ICCM availability at HP for sick children were about five times more likely to utilize the service than those who were not aware of the ICCM service availability at HP for sick children. This finding is congruent with findings from other studies done in Ethiopia and Kenya. ${ }^{18,20}$ This might indicate that more awareness of ICCM service availability at HP will scaleup the healthcare-seeking behavior of caregivers.

Caregivers residing within 30 minutes on foot traveling distance from home to HP in their kebele were about five times more likely to utilize ICCM at a HP as compared to those whose distance is more than 120 minutes from home to HP. This finding is in line with the results of other studies done in Ethiopia and Uganda. ${ }^{2-24}$ Although ICCM provision aims to scale-up the health care access in the community by minimizing the distance to travel, this still showed that distance is a challenge for caregivers to utilize ICCM at HPs in the study area.

Children who had symptoms of fever were about three times more likely to utilize the service than children who had diarrhea. This finding is different from the study finding in Jima zone in which children who had pneumonia

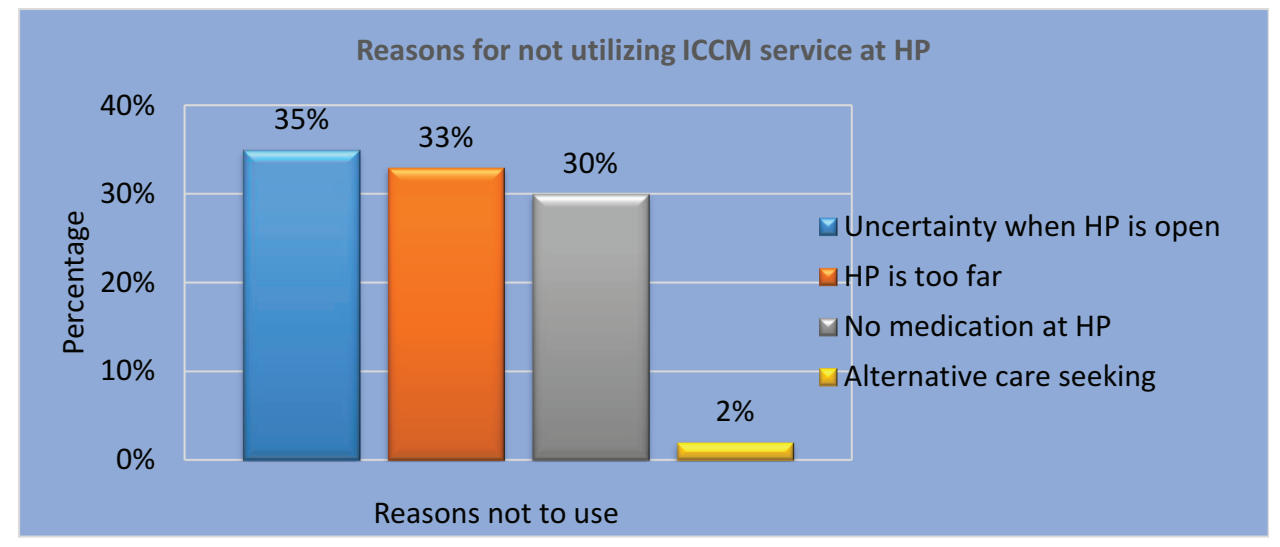

Figure 2 Reasons for not utilizing ICCM at HP in Kindo Didaye district, Ethiopia, 2019. 
Table 3 Factors Associated with ICCM Service Utilization at HP Among Sick Under-Five Children in Kindo Didaye District, Southern Ethiopia, 2019

\begin{tabular}{|c|c|c|c|c|c|}
\hline \multicolumn{2}{|l|}{ Variables } & \multicolumn{2}{|c|}{ ICCM Utilization } & \multicolumn{2}{|l|}{ OR $(95 \% \mathrm{Cl})$} \\
\hline & & \multirow{3}{*}{$\begin{array}{l}\text { Yes } \\
49 \\
17\end{array}$} & \multirow{3}{*}{$\begin{array}{l}\text { No } \\
337 \\
221\end{array}$} & \multirow{3}{*}{$\begin{array}{l}\text { COR }(95 \% \mathrm{Cl}) \\
\mathrm{I} \\
0.53(0.18-0.95)\end{array}$} & \multirow{3}{*}{$\begin{array}{l}\text { AOR }(95 \% \mathrm{CI}) \\
\mathrm{I} \\
0.79(0.47-\mathrm{I} .18)\end{array}$} \\
\hline Maternal age in years & $<30$ & & & & \\
\hline & $\geq 30$ & & & & \\
\hline \multirow[t]{3}{*}{ The educational level of a mother } & Unable to read and write & 50 & 445 & 1 & I \\
\hline & Grade I-8 & 10 & 93 & $1.04(0.5 I-2.14)$ & $0.97(0.47-2.29)$ \\
\hline & Grade $\geq 9$ & 6 & 20 & $0.37(0.14-1.67)$ & $0.33(0.10-1.07)$ \\
\hline \multirow[t]{3}{*}{ Wealth index } & Poor & 30 & 159 & $3.15(1.53-6.50)$ & $2.99(1.37-6.53)^{*}$ \\
\hline & Medium & 25 & 213 & $1.96(0.91-2.84)$ & $1.68(0.88-3.20)$ \\
\hline & Rich & II & 184 & I & 1 \\
\hline \multirow[t]{5}{*}{ Age of child in months } & $0-11$ & 2 & 55 & $0.22(0.14-1.16)$ & $0.63(0.48-1.69)$ \\
\hline & $12-23$ & 12 & 74 & $0.97(0.88-2.19)$ & $1.03(0.94-2.91)$ \\
\hline & $24-35$ & 17 & 163 & $0.64(0.5 I-1.13)$ & $0.97(0.74-2.30)$ \\
\hline & $36-47$ & 13 & 134 & $0.59(0.43-1.55)$ & $0.95(0.88-1.32)$ \\
\hline & $48-49$ & 22 & 132 & 1 & 1 \\
\hline \multirow[t]{2}{*}{ Previous use of services at HP } & Yes & 63 & 457 & $4.64(1.42-15.07)$ & $6.66(1.81-24.04)^{*}$ \\
\hline & No & 3 & 101 & 1 & I \\
\hline \multirow[t]{2}{*}{ Owner of health insurance } & Yes & 37 & 413 & 1 & I \\
\hline & No & 29 & 145 & $2.23(1.32,3.76)$ & $2.63(1.45,4.76)^{*}$ \\
\hline \multirow[t]{2}{*}{ Awareness of ICCM services at HP } & Yes & 62 & 458 & $3.36(1.34,14.18)$ & $4.74(1.39,12.10)^{*}$ \\
\hline & No & 4 & 100 & 1 & 1 \\
\hline \multirow[t]{4}{*}{ Distance from home to HP (in minutes) } & $0-30$ & 24 & 45 & $4.93(1.74,13.94)$ & $5.23(1.69,10.19)^{*}$ \\
\hline & $31-60$ & 10 & 150 & $0.62(0.44,1.29)$ & $1.02(0.98,2.99)$ \\
\hline & $61-120$ & 20 & 252 & $0.73(0.63,1.53)$ & $1.20(0.96,2.06)$ \\
\hline & $>120$ & 12 & 111 & 1 & I \\
\hline \multirow[t]{3}{*}{ Type of child illness } & Fever & 32 & 193 & $2.13(1.08,4.19)$ & $2.97(1.41,6.25)^{*}$ \\
\hline & Cough & 21 & 198 & $1.36(0.87,2.80)$ & $1.67(0.87,3.20)$ \\
\hline & Diarrhea & 13 & 167 & 1 & $\mathrm{I}$ \\
\hline
\end{tabular}

Note: *Statistically significant in multivariabe logistic regression (AOR) at $\mathrm{P}$-value $<0.05$.

were more likely to utilize service than children who had diarrhea. ${ }^{20}$ Even though it is a plausible hypothesis, this might be due to seasonal and other socio-demographic differences linked with common childhood illnesses. This study was done during the high malaria transmission season in Ethiopia, May, so that fever might be more prevalent and needed the attention of caregivers.

This study also revealed that caregivers are not seeking ICCM from their respective HPs due to the HP being located too far from their home, uncertainty as to the time when the HP is open and whether the HP has no necessary medication, all mentioned as main reasons. This finding is supported by another study conducted in other part of the country. ${ }^{10}$ This indicates that still there are ample challenges for caregivers, such as the accessibility of HP, lack of awareness on working hours, and lack of commodity supplies at HPs.

In this study, the authors tried to minimize recall bias by asking respondents for events that happened to their child within the last two weeks preceding the survey. Social desirability bias in which people might be afraid to admit that they are not visiting HPs in their respective kebele was fixed by recruiting health professional data collectors from other districts. However, future researches need to incorporate qualitative assessments to explore other factors that may support the quantitative assessment so that strong recommendations will be forwarded. 


\section{Conclusion}

This study revealed that the utilization of ICCM at HPs for under-five sick children with cough, diarrhea, and fever in the district was very low, and halve of the sick children in the study area were not seeking out ICCM. Household income, previous utilization of health services at HP for child illness, ownership of community health insurance, the caregiver's awareness of ICCM availability at HP for sick children, walking distance from home to HP in their kebele and type of child illness were found to be significantly associated with ICCM utilization at HP.

Therefore, it is crucial to improve community awareness on ICCM at HPs through community-based platforms (e.g. forums, home visits, meetings) and structures (e.g. women development army, 1-to-5 networks, and volunteer community health workers). It is also important to avail additional HPs as near to many and equip them with the necessary medical supplies to address the problems of the majority.

\section{Abbreviations}

HEWs, health extension workers; ICCM, integrated community case management of common childhood illnesses; $\mathrm{HP}$, health post; HH, household; L10K, the last 10 kilometers of JSI project; COR, crude odds ratio; AOR, adjusted odds ratio; $\mathrm{CI}$, confidence interval.

\section{Data Sharing Statement}

All the datasets used and/or analyzed during the current study are included in the manuscript and additional information is available from the corresponding author on reasonable request.

\section{Ethics Approval and Informed Consent}

We obtained ethical approval from Ethical Review Committee of the College of Health Science at Wolaita Sodo University with Ref. No. CARD:335/334/11. We had obtained verbal informed consent from participants after informing them of the purpose, benefit, risk, confidentiality of the information and voluntary nature of participation in the study. The aforementioned ethical review committee had approved the process of the consent and we had conducted the study in accordance with the Declaration of Helsinki. We linked under-five sick children, who were sick and not on treatment during the data collection time, to the nearby HP to initiate appropriate treatment.

\section{Author Contributions}

Asefa Berhanu had led the field data collection and analysis. All authors made substantial contributions to conception and design, analysis and interpretation of data; took part in drafting the article or revising it critically for important intellectual content; agreed to submit to the current journal; gave final approval of the version to be published; and agree to be accountable for all aspects of the work.

\section{Funding}

Authors received no financial support for the research, authorship, and/or publication of this article.

\section{Disclosure}

The authors declare no conflicts of interest and no potential conflicts of interest with respect to the research, authorship, or publication of this article.

\section{References}

1. United Nations Inter-agency Group for Child Mortality Estimation (UN IGME). Levels \& Trends in Child Mortality: Report 2019, Estimates Developed by the United Nations Inter-Agency Group for Child Mortality Estimation. New York: United Nations Children's Fund; 2019. Available from: www.childmortality.org. Accessed November 13, 2020.

2. United Nations Inter-agency Group for Child Mortality Estimation (UN IGME). Levels \& Trends in Child Mortality: Report 2017, Estimates developed by the United Nations Inter-agency Group for Child Mortality Estimation. New York: United Nations Children's Fund; 2017. Available from: www.childmortality.org. Accessed November 13, 2020.

3. Ethiopian Federal Ministry of Health. National Implementation Plan for Community Management of Common Childhood Diseases. Addis Ababa: Federal Ministry of Health; 2010.

4. Ethiopian Federal Ministry of Health. Health Extension Program in Ethiopia Profile. Addis Ababa: Health Extension and Education center. Ministry of Health; 2007.

5. Bernadette D, Awa S, Humphreys N, Shelby W, Mark Y. Integrated community case management of childhood illness. Am J Trop Med Hyg. 2016;94(3).

6. Bryce J, Friberg IK, Kraushaar D. LiST as a catalyst in program planning: experiences from Burkina Faso, Ghana and Malawi. Int J Epidemiol. 2010;39(Supplement 1):i40-i47. doi:10.1093/ije/ dyq020

7. Schellenberg JA, Victora CG, Mushi A. Inequities among the very poor: health care for children in rural southern Tanzania. Lancet. 2003;361(9357):561-566. doi:10.1016/S0140-6736(03)12515-9

8. Ameha A, Legesse H, Sylla M, et al. The effect of community-based newborn care intervention on service utilization for sick newborn and children. Ethiop Med J. 2019;3.

9. Federal Ministry of Health. National Strategy for Child Survival in Ethiopia (2015/16 - 2019/20). Addis Ababa: FMOH; 2015.

10. UNICEF/PATH (2016). Literature review on barriers to health extension services. Draft Report; 2016

11. Legesse H, Degefie T, Hiluf M, et al. National scale-up of integrated community case management in rural Ethiopia: implementation and early lessons learned. Ethiop Med J. 2014;52(Supp.3):15-26. 
12. Shaw B, Amouzou A, Miller NP, Tafesse M, Bryce J, Surkan PJ. Access to integrated community case management of childhood illnesses services in rural Ethiopia: a qualitative study of the perspectives and experiences of caregivers. Health Policy Plan. 2015;31 (5):656-666. doi:10.1093/heapol/czv115

13. A Survey of The Last Ten Kilometers Project. Integrated community case management survey in Amhara, SNNP, and Tigray Regions. 2013. Available from: www.110k.jsi.com. Accessed November 13, 2020 .

14. Andersen RM, Newman JF. Andersen and newman's framework of health services utilization. Health Serv Res. 1995;8(3):184-199.

15. Miller NP, Agbessi A, Mengistu T, et al. Integrated community case management of childhood illness in Ethiopia: implementation strength and quality of care. Am J Trop Med Hyg. 2014;91 (2):424-434. doi:10.4269/ajtmh.13-0751

16. Hosmer DW, Lemeshow S. Applied Logistic Regression. 2nd ed. ohn Wiley \& Sons, Inc., New York. doi:10.1002/0471722146

17. Marsha B. Factors Affecting Utilization of Integrated Community Case Management of Common Childhood Illness in Agarfa Woreda, Oromia Region, Ethiopia [Unpublished Thesis]. 2014.

18. Kisia J, Nelima F, Otieno DO, et al. Factors associated with utilization of community health workers in improving access to malaria treatment among children in Kenya. Malar J. 2012;11(1):248. doi:10.1186/1475-2875-11-248

19. Mukanga D, Tibenderana JK, Peterson S, et al. Access, acceptability and utilization of community health workers using diagnostics for case management of fever in Ugandan children: a cross-sectional study. Malar J. 2012;11(1):121. doi:10.1186/1475-2875-11-121
20. Shaw B, Amouzou A, Miller NP, et al. Determinants of utilization of health extension workers in the context of scale-up of integrated community case management of childhood illnesses in Ethiopia. Am J Trop Med Hyg. 2015;93(3):636-647.

21. Atnafu DD, Tilahun H, Alemu YM. Community-based health insurance and healthcare service utilisation, North-West, Ethiopia: a comparative, cross-sectional study. BMJ Open. 2018;8(8): e019613. doi:10.1136/bmjopen-2017-019613

22. Addis Ashenafi AM, Ameha A, Erbo A, Getachew N, Betemariam W. Effect of the health extension program and other accessibility factors on care-seeking behaviors fore common childhood illnesses in rural Ethiopia. Ethiop Med J. 2014;52(Supp 3):57.

23. Mebratie AD, Van de Poel E, Yilma Z, et al. Healthcare-seeking behaviour in rural Ethiopia: evidence from clinical vignettes. $B M J$ Open. 2014;4(2):e004020. doi:10.1136/bmjopen-2013-004020

24. Rutebemberwa E, Kallander K, Tomson G, Peterson S, Pariyo G. Determinants of delay in care-seeking for febrile children in eastern Uganda. Trop Med Int Health. 2009;14(4):472-479. doi:10.1111/ j.1365-3156.2009.02237.x

\section{Publish your work in this journal}

Pediatric Health, Medicine and Therapeutics is an international, peerreviewed, open access journal publishing original research, reports, editorials, reviews and commentaries. All aspects of health maintenance, preventative measures and disease treatment interventions are addressed within the journal. Practitioners from all disciplines are invited to submit their work as well as healthcare researchers and patient support groups. The manuscript management system is completely online and includes a very quick and fair peer-review system. Visit http://www.dovepress.com/testimonials.php to read real quotes from published authors. 